\title{
Inhibition of 5-HT Neurotransmission Increases Clonidine Protective Effects on Naloxone-induced Conditioned Place Aversion in Morphine-dependent Rats
}

\author{
Stéphanie Caillé*,', Luis Stinus', Emilio F Espejo², Philippe De Deurwaerdère', Umberto Spampinato' and \\ George F Koob ${ }^{3}$ \\ 'Lab de Neuropsychobiologie des Désadaptations, Université de Bordeaux II, Bordeaux, France; ${ }^{2}$ Depto de Fisiologia Médica y Biofísica, \\ Universidad de Sevilla, Sevilla, Spain; ${ }^{3}$ Department of Neuropharmacology, The Scripps Research Institute, La Jolla, CA, USA
}

\begin{abstract}
Previous pharmacological studies have implicated serotonergic brain systems in opiate-withdrawal-precipitated conditioned place aversion. To assess this hypothesis, we tested the effects of either (i) a near-total 5,7-dihydroxytryptamine-induced lesion (90\% depletion) or (ii) an acute serotonin (5-HT) inhibition induced by the specific stimulation of 5-HTIA autoreceptors (8-OHDPAT 5$100 \mu \mathrm{g} / \mathrm{kg}$ ), on naloxone-induced conditioned place aversion in morphine-dependent rats. Morphine dependence was induced by the implantation of morphine slow-release pellets. The protective properties of clonidine (an alpha-2 adrenergic agonist classically given for opiate detoxification) were also tested after inhibition of 5-HT transmission. Serotonergic lesions in morphine-dependent rats failed to alter naloxone-induced conditioned place aversion but increased the sensitivity to the protective effects of clonidine. Acute neuropharmacological blockade of serotonin transmission also potentiated the clonidine effects on naloxone-induced conditioned place aversion. When combined with the 5-HTIA agonist 8-OHDPAT, clonidine was also found to be more potent. Further understanding of this serotonin/noradrenaline interaction might help devise new therapeutic treatments for the acute opiate withdrawal syndrome. Neuropsychopharmacology (2003) 28, 276-283. doi:I 0.1038/sj.npp. 1300033
\end{abstract}

Keywords: serotonin; opiate; aversion; clonidine; 8-OHDPAT

\section{INTRODUCTION}

Chronic exposure to opiates induces a strong dependence state. Cessation of the drug administration or injection of a $\mu$-opioid antagonist (eg naloxone) leads to a severe withdrawal syndrome characteristic of opiate dependence (Gellert and Holtzman, 1978; Gold et al, 1994). In addition, opiate withdrawal precipitates both an aversive motivational state (measured in a place conditioning paradigm) and somatic symptoms (rated over a period of time) (Schulteis et al, 1994). Clonidine, an alpha-2 adrenergic agonist classically used for opiate detoxification in heroin addicts (Charney et al, 1981; Gold et al, 1978; Macedo et al, 2000), alleviates both aversive and somatic withdrawal symptoms in morphine-dependent rats (Caille et al, 1999b). The neurobiological bases of opiate withdrawal have been widely investigated. The amygdala, bed nucleus of the stria terminalis and nucleus accumbens systems have been

* Correspondence: Dr S Caillé, Department of Neuropharmacology, CVN-7, The Scripps Research Institute, 10550 N Torrey Pines Road, La Jolla, CA 92037, USA, Tel: 858-784-7305, Fax: 858-784-7405, E-mail: scaille@scripps.edu

Received 13 April 2002; revised 5 July 2002; accepted 10 July 2002 Online publication: 15 July 2002 at http://www.acnp.org/citations/ Npp07| 502349 implicated in the withdrawal-induced aversive behavior of morphine-dependent rats (Delfs et al, 2000; Heinrichs et al, 1995; Stinus et al, 1990). In addition, caudal structures such as periaqueductal gray matter (PAG) (Christie et al, 1997; Maldonado et al, 1992), where the serotonergic fibers are grouped (Bjorklund et al, 1984), have been implicated in the somatic withdrawal syndrome.

The median raphe (MR) and dorsal raphe (DR) nuclei are the major serotonin-containing nuclei of the brainstem and the main source of 5-HT fibers projecting to the telencephalon and diencephalon (Azmitia and Segal, 1978; Vertes, 1991). Acute injection of morphine increases serotonin (5-HT) extracellular levels in the rat forebrain (Tao and Auerbach, 1995), which modulates dopaminergic activity within the nucleus accumbens (Spampinato et al, 1984). The regulation of 5-HT release is altered during chronic exposure to morphine. Thus, 5-HT has been hypothesized to be one of the factors involved in the changes in physiology and behavioral state which occur during opiate withdrawal. However, several findings have suggested that $5-\mathrm{HT}$ is not responsible for the physical symptoms of withdrawal (Blasig et al, 1976; Silverstone et al, 1993), except for a possible role in jumping behavior (Cervo et al, 1983; Way et al, 1968). For example, it has been shown that serotonergic transmission blockade, either by 
specific 5-HT lesion (Ho et al, 1972) or a 5-HT antagonist (Cervo et al, 1981; Samanin et al, 1980) along with chronic morphine treatment, reduces the development of jumping behavior during morphine withdrawal. Concerning the role of serotonin in the motivational aspect of morphine withdrawal, there are conflicting data. Rafieian-Kopaei et al (1995) have demonstrated that increased 5-HT neurotransmission by way of specific reuptake inhibitors blocked naloxone-induced conditioned place aversion in morphinedependent rats. However, similar effects have been observed with decreased 5-HT transmission by the use of selective 5HT3 antagonists (Acquas et al, 1990; Higgins et al, 1991). Thus, the role of 5-HT neurotransmission in opiatewithdrawal-induced conditioned place aversion remains unclear.

The present study was designed to evaluate whether or not the 5-HT systems were critically responsible for the withdrawal-induced aversive symptoms in morphinedependent rats. Therefore, a lesion technique using 5,7dihydroxytryptamine was developed in the laboratory in order to destroy most of the 5-HT neurons (90\% depletion) arising from the DR and MR nuclei. The role of 5-HT in naloxone-induced conditioned place aversion in morphinedependent rats was tested by (i) lesions of central serotonergic systems and (ii) an acute blockade of serotonergic systems (injection of low doses of the 5HT1A agonist 8-OH-DPAT; Goodwin et al, 1987). Finally, the potential interaction of serotonin systems and noradrenergic systems in naloxone-induced conditioned place aversion was tested by examining the effect of the noradrenergic alpha-2 agonist clonidine in the above lesion and neuropharmacological models.

\section{MATERIALS AND METHODS}

\section{Animals}

A total of 368 male Sprague-Dawley rats (IFFA-CREDO, Lyon, France) weighing 220-240 g at the beginning of the experiments were used. Animals were housed by four in cages located in a thermoregulated room $\left(22^{\circ} \mathrm{C}\right)$ with a $12-$ $12 \mathrm{~h}$ light-dark cycle (light from 8:00 am to 8:00 pm). Food and water were available ad libitum. These conditions were maintained constant throughout the experiments. All manipulations and observations were made during the light phase of the circadian cycle.

The experiments were carried out in accordance with the Declaration of Helsinki, the Guide for the Care and Use of Laboratory Animals as adopted and promulgated by the US National Institutes of Health, the European Communities Council Directives (86/609/EEC, 24 November 1986), and the French Directives concerning the Use of Laboratory Animals (Decret 87-848, 19 October 1987).

\section{Drugs}

The following compounds were used in this study: desmethylimipramine (Sigma Co., St Louis, MO, USA), nomifensin maleate (Research Biochemicals International, Natick, MA, USA), 5,7-dihydroxytryptamine creatinine sulfate (5,7-DHT) (Sigma), ( \pm )-8-hydroxy-dipropylaminotetralin hydrobromide (8-OH-DPAT; a 5-HT1A agonist,
Research Biochemicals International), morphine pellets (National Institute on Drug Abuse, Bethesda, MD, USA), naloxone hydrochloride (Research Biochemicals International) and clonidine hydrochloride (Research Biochemicals International). All drugs were dissolved in $\mathrm{NaCl}$ isotonic solution $(0.9 \%$ in water; $1 \mathrm{ml} / \mathrm{kg})$, except for $5,7-\mathrm{DHT}$, whose vehicle consisted of $\mathrm{NaCl}$ isotonic solution $(0.9 \%$ in water) containing $0.1 \mathrm{mg} / \mathrm{ml}$ of ascorbic acid.

\section{Surgery}

Serotonergic innervation arising from the DR and the MR was almost totally destroyed by multiple intracerebral injections of 5,7-DHT aimed at DR and MR 5-HT nuclei. Rats were anesthetized with chloral hydrate $(270 \mathrm{mg} / \mathrm{kg}$ i.p. in isotonic saline, $1 \mathrm{ml} / \mathrm{kg}$ ) and placed in a Kopf stereotaxic apparatus with the incisor bar set $5.0 \mathrm{~mm}$ above the interaural line. The 5,7-DHT solution contained $2 \mu \mathrm{g}$ base in $1 \mu \mathrm{l}(1 \mu \mathrm{g}$ base $=2.099 \mu \mathrm{g}$ 5,7-DHT creatinine sulfate). The rate of injection was $1 \mu \mathrm{l}$ over $100 \mathrm{~s}$. The following coordinates are expressed in $\mathrm{mm}$ : $\mathrm{L}$ for lateral from the midline, AP for anteroposterior from bregma, and $\mathrm{V}$ for vertical from the skull surface. Coordinates of injection sites were verified histologically on four animals of the same group $24 \mathrm{~h}$ before each experiment. Four bilateral targets were chosen according to the distributional map of serotonin-immunoreactive neurons in the rat brain (Bjorklund et al, 1984); $4 \mu \mathrm{g}$ of 5,7-DHT was injected at each site: (I) two sites located in the ventral part of the PAQ matter (DR), $\mathrm{L} \pm 0.5, \mathrm{AP}-4.4, \mathrm{~V}-6.3$ and $\mathrm{L} \pm 0.5, \mathrm{AP}-5.4, \mathrm{~V}$ -6.2 ; (II) the third site located just above the interpeduncular nucleus, $\mathrm{L} \pm 0.5, \mathrm{AP}-4.4, \mathrm{~V}-8.7$; and (III) the fourth site located at the bottom part of the tectospinal tract (MR), $\mathrm{L} \pm 0.5, \mathrm{AP}-5.4, \mathrm{~V}-9.2(N=104)$. Sham-operated rats received vehicle injections $(N=108) .30 \mathrm{~min}$ before the 5,7-DHT or vehicle injections, rats were pretreated with the noradrenaline (NA) reuptake inhibitor desmethylimipramine (10 mg/kg i.p.) (Beique et al, 1998), and the dopamine (DA) reuptake inhibitor nomifensin $(10 \mathrm{mg} / \mathrm{kg}$ i.p.) (Dugast et $\mathrm{al}, 1994)$, to protect noradrenergic and dopaminergic neurons from the neurotoxic effects of 5,7-DHT. All experiments began after a 1-week postoperative recovery.

\section{Induction of Opiate Dependence}

Morphine dependence was induced by subcutaneous implantation (lower back) under rapid, deep anesthesia (halothane/air; induction $4 \% \mathrm{v} / \mathrm{v}$ for $10 \mathrm{~s}$ followed by $1.5 \%$ $\mathrm{v} / \mathrm{v}$ for $30 \mathrm{~s}$ ) of two slow-release morphine pellets (each morphine pellet contains $75 \mathrm{mg}$ of morphine base, $N=368 \times 2)$. Full dependence on morphine is achieved $24 \mathrm{~h}$ after implantation of the morphine pellet and remains constant for 15 days (Gold et al, 1994).

\section{Place Aversion Conditioning}

During the 4 days preceding the experiment, the rats were handled in order to familiarize them with the manipulations and to reduce stress. The apparatus and procedure used to produce a reliable conditioned place aversion have been described in detail elsewhere (Stinus et al, 2000, 1990). Briefly, the apparatus consisted of three identical rectan- 
gular boxes $(\mathrm{A}, \mathrm{B}, \mathrm{C})(40 \times 33 \times 34 \mathrm{~cm})$ arranged radially $\left(120^{\circ}\right.$ to each other) and accessible from a triangular central compartment. Distinctive visual and tactile cues distinguished the three compartments (A: black dotted white walls and smooth floor; B: black striped white walls and medium rough floor; $\mathrm{C}$ : white walls and rough floor). Each compartment was equipped with six infrared photocells for automated detection and recording of the animal's position by computer. Four of these set-ups were located in a dimly illuminated testing room (15 W red lights) supplied with white noise. The place conditioning experiment consisted of three phases: a preconditioning phase, a conditioning phase and a testing phase.

Preconditioning phase. On day 4, postpellet implantation, rats were placed in the central triangular compartment and allowed to explore freely the entire apparatus for $20 \mathrm{~min}$. For each rat, two compartments in which the rats spent similar times were randomly paired either with naloxone (drug-paired, D0) or saline (saline-paired, S0). The third compartment was not paired with any injection (N0). After assigning the compartments, we checked that there were no statistically significant differences between the time spent in the drug- and the saline-paired compartments during the preconditioning phase (D0 vs S0). This important step in the experimental procedure eliminates possible bias prior to conditioning.

Conditioning phase. On days 5, 7 and 9 postpellet implantation, before being confined to their preselected saline-paired compartment for $20 \mathrm{~min}$, rats were injected with vehicle. On days 6,8 and 10 postpellet implantation, rats received naloxone immediately before being confined to their preselected drug-paired compartment for $20 \mathrm{~min}$.

Testing phase. On days 11 and 12 postpellet implantation (ie 24 and $48 \mathrm{~h}$ after the end of the conditioning phase), rats were allowed to explore the entire apparatus freely for 20 min. We measured the time spent in the drug-paired compartment (D), in the saline-paired compartment (S) and in the neutral compartment $(\mathrm{N})$. D, S and $\mathrm{N}$ represented the mean values for each rat during these two testing sessions. $\mathrm{D}-\mathrm{D} 0$ represented the intensity of naloxone-induced aversion, and $\mathrm{S}-\mathrm{SO}$ and $\mathrm{N}-\mathrm{N} 0$ indicated where the rats went when they avoided the drug-paired compartment.

\section{Measurement of Tissue Levels of Biogenic Amines}

At the end of the experiments, when the acute effects of morphine abstinence had ceased (ie 1-month postpellet implantation), lesioned $(n=20)$ and sham-operated rats $(n=10)$ were killed by decapitation. Brains were rapidly removed, and the cortex, striatum and hippocampus were dissected bilaterally at $4^{\circ} \mathrm{C}$. Dissected structures were immediately frozen on dry ice and stored at $-80^{\circ} \mathrm{C}$ until biochemical assays. DA, NA and serotonin (5-HT) contents were measured in the dissected brain regions by HPLC coupled with electrochemical detection. Tissue samples were homogenized in $200 \mu \mathrm{l}$ of $0.1 \mathrm{~N} \mathrm{HClO}_{4}$ and centrifuged at $11000 \mathrm{rpm}$ for $30 \mathrm{~min}$ at $4{ }^{\circ} \mathrm{C}$. Aliquots $(10-20 \mu \mathrm{l})$ of the supernatants were injected into the HPLC system after dilution with appropriate volumes of mobile phase. The mobile phase was as follows: $60 \mathrm{mM} \mathrm{NaH} \mathrm{NO}_{4}, 0.1 \mathrm{mM}$ disodium EDTA, $0.2 \mathrm{mM}$ octane sulfonic acid, 7\% methanol, adjusted to $\mathrm{pH} 3.9$ with orthophosphoric acid and filtered through a $0.22 \mu \mathrm{m}$ Millipore filter. This mobile phase was delivered at $1.2 \mathrm{ml} / \mathrm{min}$ (Pump 116, System Gold, Beckman, Paris, France) through a Chromasyl column (C8, $150 \times 4.6 \mathrm{~mm}^{2}, 5-\mu \mathrm{m}$, Touzard \& Matignon, Paris, France) protected by a Brownlee-Newgard precolumn (RP-8, $15 \times 3.2 \mathrm{~mm}, 7-\mu \mathrm{m})$. A refrigerated injector (Injector 507, System Gold, Beckman, Paris, France) was used. NA, DA and 5-HT were detected by a coulometric system (Coulochem II, ESA, Paris, France) coupled to a dual-electrode analytic cell (ESA model 5011) and a conditioning cell (ESA model 5021). The conditioning cell was set at $+100 \mathrm{mV}$, the first electrode at $+350 \mathrm{mV}$ and the second at $-270 \mathrm{mV}$. Results were expressed in $\mathrm{pg} / \mathrm{mg}$ of tissue and each value was the mean \pm SEM.

\section{Experiment 1: Effect of Lesion of 5-HT Neurons on Naloxone-induced Conditioned Place Aversion in Morphine-dependent Rats}

A total of 44 5,7-DHT-lesioned and 48 sham-operated morphine-dependent rats were used. Dependence was induced by subcutaneous implantation of two morphine pellets. The naloxone-induced place aversion-conditioning paradigm was initiated on the fourth day following implantation. During the conditioning phase (three pairings) the following doses of naloxone were used: $0,1.8,3.7$, 7.5 and $15 \mu \mathrm{g} / \mathrm{kg}$ s.c. (Nal-0, Nal-1.8, Nal-3.7, Nal-7.5 and Nal-15).

\section{Experiment 2: Effect of Lesion of 5-HT Neurons on Ability of Clonidine to Reverse Naloxone-induced Conditioned Place Aversion in Morphine-dependent Rats}

A total of 60 5,7-DHT-lesioned and 60 sham-operated morphine-dependent rats were assessed for place aversion conditioning. After a preconditioning test on the fourth day post pellet implantation, the conditioning phase began. On each naloxone pairing day (naloxone $15 \mu \mathrm{g} / \mathrm{kg}$ s.c.), rats received an injection of clonidine $1 \mathrm{~h}$ before the naloxone injection (ie, $1 \mathrm{~h}$ before confinement in the drug-paired side of the apparatus; Caille et al, 1999b). The following doses of clonidine were tested: $0,25,50,100,200,400 \mu \mathrm{g} / \mathrm{kg}$ i.p. for sham rats and $6,12,25,50,100 \mu \mathrm{g} / \mathrm{kg}$ i.p. for $5,7-\mathrm{DHT}$ lesioned rats (Clo-0, Clo-6, Clo-12, Clo-25, Clo-50, Clo-100, Clo-200 and Clo-400).

\section{Experiment 3: 8-OHDPAT Effects on Clonidine Protection of Naloxone-induced Condition Place Aversion: A Dose-Response Study with 8-OHDPAT}

A total of 101 rats were made dependent on morphine and were assessed for naloxone-induced place aversion. On the fourth day, the conditioning phase began with naloxone $15 \mu \mathrm{g} / \mathrm{kg}$ s.c. (Nal-15). At each naloxone-pairing day, clonidine $50 \mu \mathrm{g} / \mathrm{kg}$ i.p. (Clo-50) was injected $60 \mathrm{~min}$ before naloxone. To induce acute inhibition of 5-HT transmission, rats also received injections of 8 -OH-DPAT $20 \mathrm{~min}$ before naloxone. Doses of $8-\mathrm{OH}-\mathrm{DPAT}$ tested were $0,5,10,25,50$, $100 \mu \mathrm{g} / \mathrm{kg}$ s.c., chosen based on their autoreceptor selectivity 
(Goodwin et al, 1987) (DPAT-0, DPAT-5, DPAT-10, DPAT25, DPAT-50 and DPAT-100).

Different control groups were formed to verify the specificity of any effect on naloxone-induced conditioned place aversion. First, the appetitive properties of 8-OHDPAT were tested: Nal-0+Clo-0+DPAT-50. Second, it was important to examine the ability of 8-OHDPAT to reverse the aversion on its own: Nal-15+Clo-0+DPAT-50. Finally, since it has been shown that clonidine has some appetitive properties at very high doses (Asin and Wirtshafter, 1985; Tierney et al, 1988), it was important to determine if there was any influence of 8-OHDPAT on clonidine properties: Nal-0+Clo-50+DPAT-50.

\section{Experiment 4: 8-OHDPAT Effects on Clonidine Protection of Naloxone-induced Conditioned Place Aversion: A Dose-response Study with Clonidine}

This experiment was performed on 55 morphine-dependent rats according to the same schedule as in Experiment 3. Conditioned place aversion was induced by naloxone (Nal15) with the group Nal-15+Clo-0+DPAT-0 being the same as in Experiment 3. Acute inhibition of 5-HT activity was produced by an injection of $8-\mathrm{OH}-\mathrm{DPAT}$ (DPAT-50). The DPAT-50 dose was used because it was found to be the most effective (Experiment 3), being specific for 5-HT autoreceptor stimulation. It was injected subcutaneously at each naloxone pairing, $20 \mathrm{~min}$ before naloxone. The following doses of clonidine were used: $0,6.25,12.5,25$ and $50 \mu \mathrm{g} / \mathrm{kg}$ i.p. The group Nal-15+Clo-50+DPAT-50 was the same as in Experiment 3.

\section{Statistical Analysis}

Tissue levels of biogenic amines: differences between 5,7DHT-lesioned and sham-operated groups were tested using a two-tailed Student's $t$-test.

The conditioned place aversion data values, which did not follow a normal distribution, were analyzed with the nonparametric Kruskal-Wallis test and Wilcoxon signed rank test. For each pharmacological treatment, the time spent in the three compartments before the conditioning phase was compared to the time spent in these same compartments during the test.

\section{RESULTS}

\section{Biochemical Verification of 5-HT Lesion}

Bilateral multiple injections of 5,7-DHT into the DR and MR nuclei and in the vicinity of the interpeduncular nucleus (which is the main source of the ascending serotonergic ascending fibers) produced an almost total lesion of ascending serotonergic innervation. Almost complete depletion of 5 -HT was observed in the cortex $(-88 \%$, $p<0.001)$, in the hippocampus $(-88 \%, p<0.001)$ and in the striatum $(-99.6 \%, p<0.001)$. When expressing the depletion as 5-HT levels as a percentage of control values (mean \pm SEM; median, first and third quartile ranges), our results indicate (i) in cortex: $12 \pm 3 \% ; 0 \%, 0$ and $28 \%$; (ii) in hippocampus: $12 \pm 8 \% ; 0 \%, 0$ and $19 \%$; and (iii) in striatum: $1 \pm 1 \%$; $0 \%, 0$ and $0 \%$. NA was not affected in either hippocampus $(+1 \%$, NS) or cortex $(+10 \%$, NS). There was no modification of DA in striatum $(-11 \%, \mathrm{NS})$.

\section{Experiment 1: Effect of Lesion of 5-HT Neurons on Naloxone-induced Conditioned Place Aversion in Morphine-dependent Rats}

The sham-operated rats' responses are summarized in Figure 1a. An overall Kruskal-Wallis comparison showed naloxone effects on both the naloxone-paired side $(\mathrm{H}[4]=17.10, \quad p<0.001)$ and the saline-paired side $(\mathrm{H}[4]=10.07, p<0.05)$, but not on the neutral compartment (Kruskal-Wallis, NS). The following comparisons were made: D-D0, S-S0 and N-N0 (Wilcoxon signed rank test). The sham-operated rats exhibited a reliable conditioned place aversion at naloxone doses of 7.5 and $15 \mu \mathrm{g} / \mathrm{kg}$ (D-D0, $p<0.01)$. At higher doses of naloxone (7.5 and $15 \mu \mathrm{g} / \mathrm{kg})$, consistent avoided the sham-operated rats' by spending the naloxone-associated compartment much
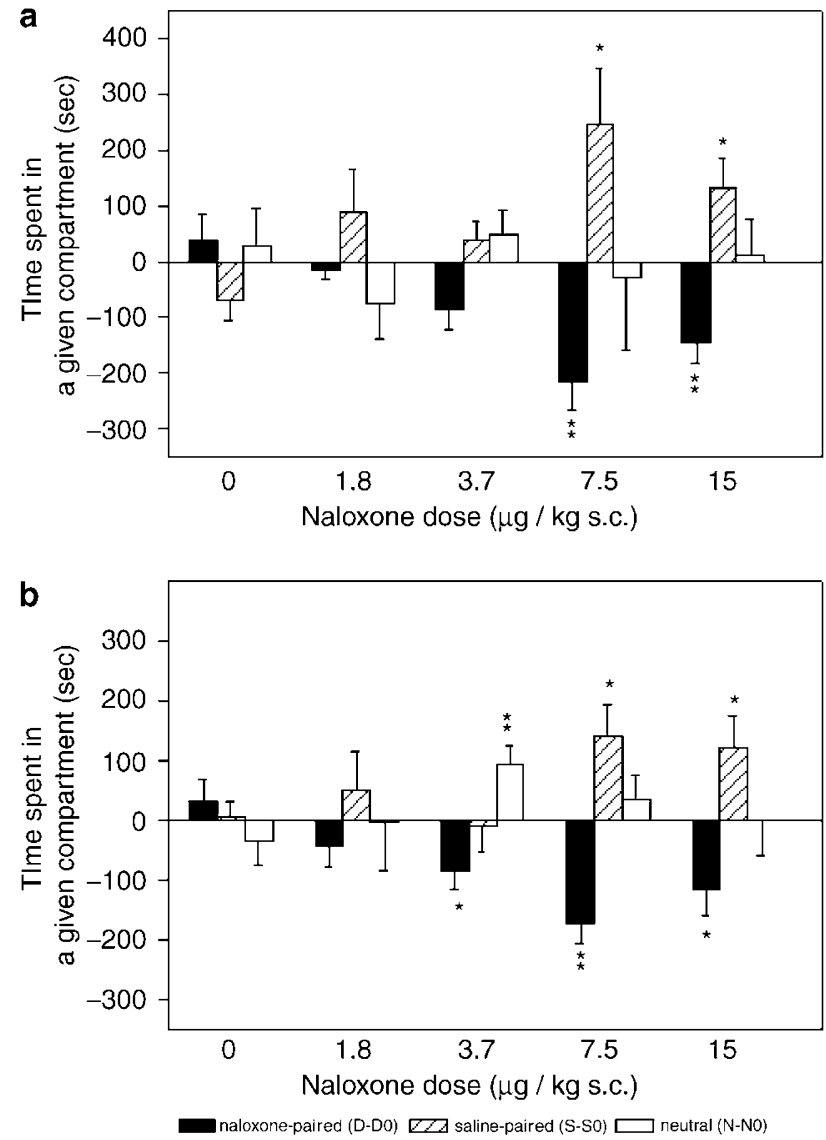

Figure I Naloxone-induced place aversion conditioning in shamoperated (a) and in 5,7-DHT-lesioned morphine-dependent rats (b). Dependence on morphine was induced by subcutaneous implantation of 2 morphine pellets. Place aversion conditioning was induced by the following doses of naloxone: $0,1.8,3.7,7.5$ and $15 \mu \mathrm{g} / \mathrm{kg}$ s.c. Each bar represents the difference of the time spent by rats in a given compartment during the test session minus the preconditioning score (D-DO, S-SO and N-NO). Black bars, naloxone-paired compartment (D-D0); striped bars, saline-paired compartment (S-SO); white bars, neutral compartment (N-N0). Wilcoxon paired test, D-D0, S-S0, N-N0: ${ }^{*} p<0.05$, ** $p<0.01$. 
longer periods in the saline-paired compartment (S-S0 for Nal-7.5, Nal-15, $p<0.05)$ than in the neutral compartment (N-N0, NS).

Modifications of time spent in each compartment for the 5,7-DHT-lesioned rats are presented in Figure 1b. An overall Kruskal-Wallis analysis indicates naloxone effects on the naloxone-paired compartment $(\mathrm{H}(4)=10.51$, $p<0.05)$ but no effects on the saline-paired and the neutral compartments (Kruskal-Wallis, both NS). Conditioned place aversion was observed for doses of naloxone as low as $3.7 \mu \mathrm{g} / \mathrm{kg}$ (D-D0, Wilcoxon, $T=-1.95, p<0.05)$ and persisted at all higher doses (D-D0: Nal-7.5, $p<0.01$; Nal$15, p<0.05)$. Although a statistically significant effect was observed for the lesioned animals at a dose of $3.7 \mu \mathrm{g} / \mathrm{kg}$, there was in fact no apparent qualitative difference between lesioned and nonlesioned animals at that dose. At higher doses of naloxone $(7.5$ and $15 \mu \mathrm{g} / \mathrm{kg}$ ), 5-HT-lesioned rats used the same strategy of avoidance as did the shamoperated rats, increasing the time spent in the saline-paired compartment (S-S0: Nal-7.5 and Nal-15, $p<0.05)$ compared to the neutral one (N-N0, NS).

Calculation of $\mathrm{ED}_{50}$ provided the evidence that clonidine was more effective in lesioned rats $\left(\mathrm{ED}_{50}=12 \mu \mathrm{g} / \mathrm{kg}\right)$ than in sham-operated rats $\left(\mathrm{ED}_{50}=114 \mu \mathrm{g} / \mathrm{kg}\right)$. Thus, this analysis confirmed a leftward shift of the protection by clonidine in the lesioned rats.

\section{Experiment 2: Effect of Lesion of 5-HT Neurons on Ability of Clonidine to Reverse Naloxone-induced Conditioned Place Aversion in Morphine-dependent Rats}

Figure 2a shows that in sham-operated rats, naloxoneinduced conditioned place aversion was observable for doses of clonidine up to $100 \mu \mathrm{g} / \mathrm{kg}$ i.p. (D-D0, Wilcoxon, Clo-0, Clo-25 and Clo-50, $p<0.05$; Clo-100, $p<0.01$ ), whereas clonidine completely blocked place aversion at doses over $100 \mu \mathrm{g} / \mathrm{kg}$ i.p. (D-Do, for Clo-200 and Clo-400, Wilcoxon NS).

In contrast, for 5,7-DHT-lesioned rats (Figure 2b), naloxone-induced place aversion was blocked starting at the dose of clonidine of $25 \mu \mathrm{g} / \mathrm{kg}$ i.p. (D-D0, Clo-25, Clo-50 and Clo-100, Wilcoxon, NS). Clonidine doses of 6 and $12 \mu \mathrm{g} /$ $\mathrm{kg}$ i.p. were ineffective (D-D0, Clo-0, Clo- 6 and Clo-12, Wilcoxon, $p<0.01)$. Lesioned rats strongly increased the time spent in the saline-paired compartment when expressing an avoidance of the naloxone side ( $\mathrm{S}-\mathrm{S} 0$, Clo- 0 and Clo-6, Wilcoxon, $p<0.05)$. They also did increase S-S0, but to a lesser extent, when aversion was already blocked (S-S0, Clo-50, Wilcoxon, $T=2.09, p<0.05$ ).

\section{Experiment 3: 8-OHDPAT Effects on Clonidine Protection of Naloxone-induced Conditioned Place Aversion: A Dose-response Study with 8-OHDPAT}

For Experiments 3 and 4, the reference group was Nal$15+$ Clo-0+DPAT-0 $\quad(\mathrm{D}-\mathrm{D} 0=-157 \pm 31$, Wilcoxon, $p<0.01)$, and control groups were Nal-15+Clo-50+DPAT$0(\mathrm{D}-\mathrm{D} 0=-171 \pm 52$, Wilcoxon, $p<0.04)$ and Nal-15+Clo$0+$ DPAT-50 (D-D0 $=-83 \pm 39$, Wilcoxon, $p<0.04)$. Kruskal-Wallis tests indicated that these three groups were identical for $\mathrm{D} / \mathrm{D} 0(\mathrm{H}(2)=2.25$, NS), for $\mathrm{S} / \mathrm{S} 0(\mathrm{H}(2)=1.71$, NS) and for $\mathrm{N} / \mathrm{NO}(\mathrm{H}(2)=0.61, \mathrm{NS})$.
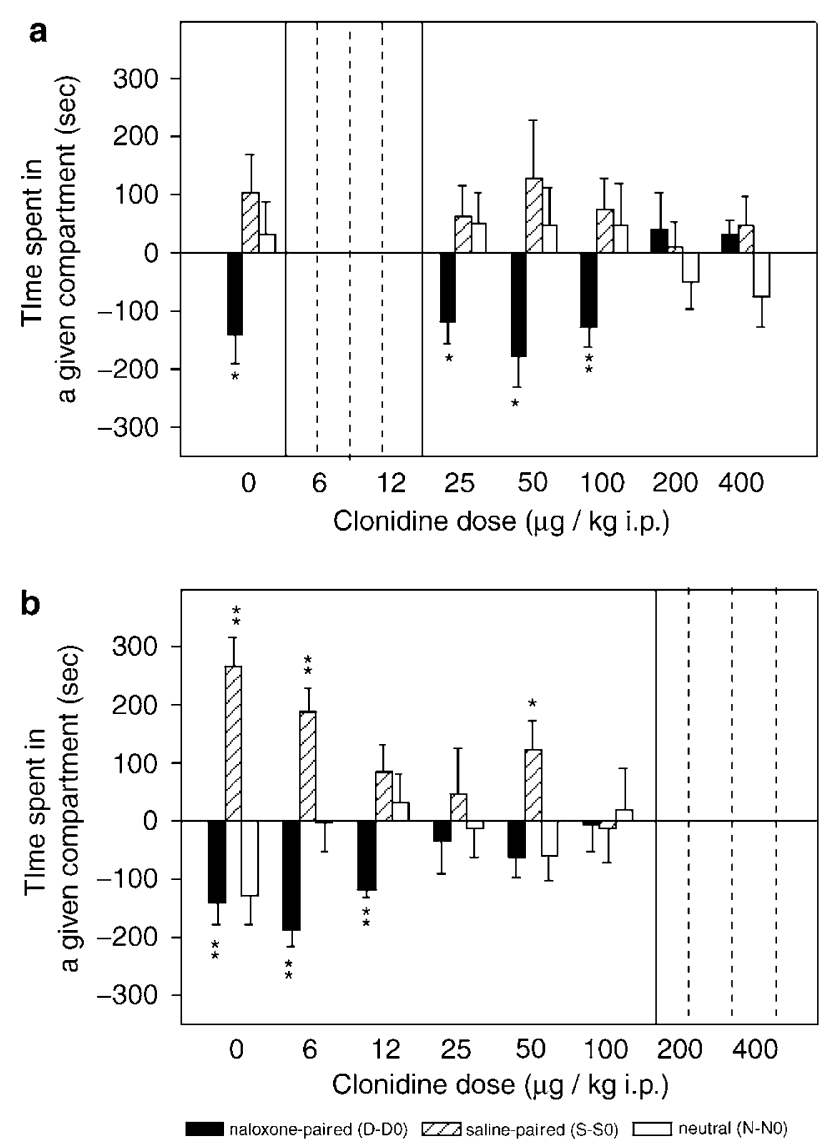

Figure 2 Dose-response clonidine alleviation of naloxone-induced conditioned place aversion in sham-operated (a) and in 5,7-DHT-lesioned (b) morphine-dependent rats (subcutaneous implantation of 2 morphine pellets). Place aversion conditioning was induced by naloxone $(15 \mu \mathrm{g} / \mathrm{kg}$ s.c.). The following doses of clonidine were tested: 0, 6, 12, 25, 50, 100, 200 and $400 \mu \mathrm{g} / \mathrm{kg}$. Clonidine was injected $60 \mathrm{~min}$ before naloxone. Each bar represents the difference of the time spent by rats in a given compartment during the test session minus the preconditioning score. Black bars, naloxone-paired compartment (D-D0); striped bars, saline-paired compartment (S-SO); white bars, neutral compartment (N-NO). Wilcoxon paired test, D/D0, S/SO, N/NO: ${ }^{*} p<0.05$, ** $p<0.01$.

The dose-response effects of 8-OHDPAT are presented in Figure 3. As expected, naloxone alone (Nal-15+Clo$0+$ DPAT -0 ) induced a reliable place aversion (Wilcoxon, $T=2.52, p<0.01$ ), and Clo-50+DPAT-0 did not reverse the place aversion induced by Nal-15 (Wilcoxon, $T=2.1$, $p<0.05)$. An overall Kruskal-Wallis analysis (seven groups) indicated that the coadministration of Clo+DPAT reversed the strong place aversion precipitated by Nal-15 in morphine-dependent rats $(\mathrm{H}[6]=18.13, p<0.005)$. Moreover, pairwise comparisons between Nal-15+Clo-0+DPAT-0 and the other groups indicated that this effect depended on the 8-OHDPAT dose. Naloxone-induced place aversion was unaffected by Clo-50+DPAT-0 or Clo-50+DPAT-5, while it was attenuated by Clo-50+DPAT-10 $(p<0.04)$ and Clo$50+$ DPAT-25 $(p=0.05)$; and completely reversed by Clo50+DPAT-50 $(p<0.005)$ and Clo-50+DPAT-100 $(p<0.002)$. The specificity of the observed effects was verified by testing additional control groups. In morphine-dependent rats, DPAT-50 did not induce either place preference or 


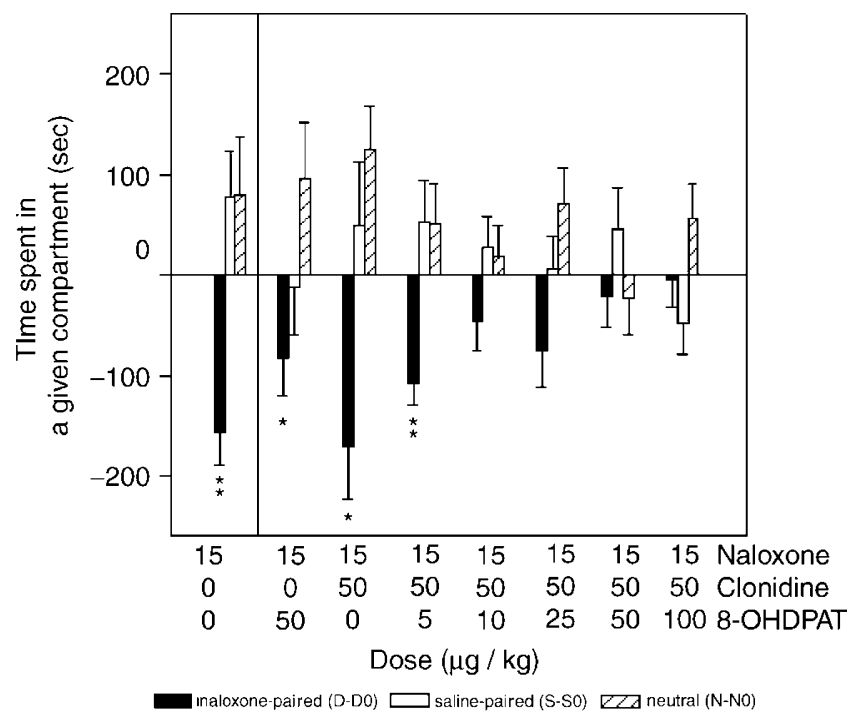

Figure 3 8-OH-DPAT enhancement of clonidine effects on naloxoneinduced conditioned place aversion. Place aversion conditioning was induced in morphine-dependent rats (subcutaneous implantation of 2 morphine pellets) by naloxone (I5 $\mu \mathrm{g} / \mathrm{kg}$ s.c.). Clonidine was given at $50 \mu \mathrm{g} / \mathrm{kg}$ i.p. The following doses of 8-OH-DPAT were tested: 0, 5, I0, 25, 50 and $100 \mu \mathrm{g} / \mathrm{kg}$ s.c. Clonidine and 8-OH-DPAT were injected 60 and $20 \mathrm{~min}$, respectively, before each naloxone administration. Each column represents the difference in time spent in a given compartment during the test session minus the preconditioning score. Black bars, naloxone-paired compartment (D-D0); striped bars, saline-paired compartment (S-SO); white bars, neutral compartment (N-N0). Wilcoxon paired test D/DO: $* p<0.05 ; * * * 0.01$

place aversion on its own (Nal-0+Clo-0+DPAT-50, $\mathrm{D}-\mathrm{D} 0=3 \pm 36 \mathrm{~s}$, Wilcoxon, D/D0, NS). Moreover, results clearly showed that 8-OHDPAT did not increase clonidine appetitive properties since Nal-0+Clo-50+DPAT-50-treated rats did not develop conditioned place preference (D$\mathrm{D} 0=91 \pm 62 \mathrm{~s}$, Wilcoxon D/D0, NS).

\section{Experiment 4: 8-OHDPAT Effects on Clonidine Protection of Naloxone-induced Conditioned Place Aversion: A Dose-response Study with Clonidine}

The dose-response effects of clonidine are presented in Figure 4. The Kruskal-Wallis test indicated that the coadministration of Clo+DPAT reversed the strong place aversion precipitated by Nal-15 in morphine-dependent rats $(\mathrm{H}[6]=18.42, p<0.005)$. Moreover, pairwise comparisons between Nal-15+Clo-0+DPAT-0 and the other groups indicated that this effect depended on clonidine dose. Naloxone-induced place aversion was unaffected by Clo- $0+$ DPAT-50 $\quad(p<0.05), \quad$ Clo-6+DPAT-50 $\quad(p<0.05) \quad$ or Clo-12 +DPAT-50 $(p<0.01)$, while it was attenuated by Clo-25 +DPAT-50, and completely reversed by Clo-50+ DPAT-50 (both doses, Wilcoxon NS). Moreover, results showed that clonidine $\mathrm{ED}_{50}$ was $28 \mu \mathrm{g} / \mathrm{kg}$ after the $8-\mathrm{OH}$ DPAT treatment.

\section{DISCUSSION}

In the present study, we tested the hypothesis that brain serotonergic systems are critical for the development of naloxone-induced conditioned place aversion in morphinedependent rats. First, we performed multiple intracerebral

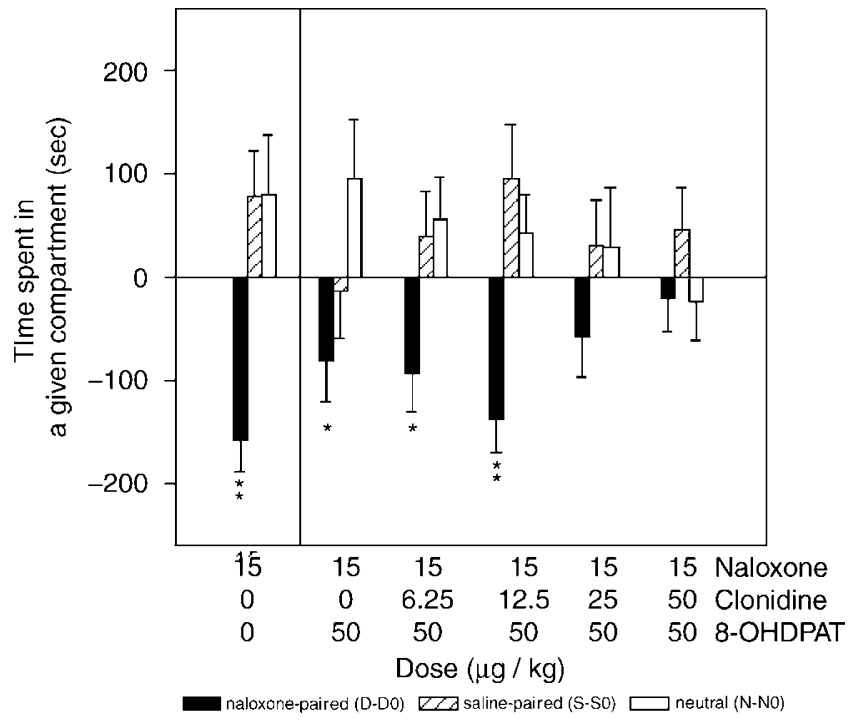

Figure 4 Dose-response attenuation by clonidine of naloxone-induced conditioned place aversion following acute inhibition of 5-HT activity. Place aversion conditioning was induced in morphine-dependent rats (subcutaneous implantation of 2 morphine pellets) by naloxone (I5 $\mu \mathrm{g} / \mathrm{kg}$ s.c.). Acute 5 -HT inhibition was produced by 8 -OH-DPAT (50 $\mu \mathrm{g} / \mathrm{kg}$ s.c.). The following doses of clonidine were tested: 0, 6.25, 12.5, 25 and $50 \mu \mathrm{g} / \mathrm{kg}$ i.p. Clonidine and 8-OH-DPAT were injected 60 and $20 \mathrm{~min}$, respectively, before each naloxone administration. Each column represents the difference in time spent in a given compartment during the test session minus the preconditioning score. Black bars, naloxone-paired compartment (D-DO); striped bars, saline-paired compartment (S-SO); white bars, neutral compartment ( $\mathrm{N}-\mathrm{N} 0)$. Wilcoxon paired test D/D0: $* p<0.05$; *** $p<0.01$.

injections of 5,7-DHT to induce a reliable, specific and nearly total $(90 \%)$ depletion of ascending 5 -HT forebrain innervation. This 5,7-DHT lesion fails to alter the naloxoneinduced aversive response in morphine-dependent rats but increases the sensitivity to the clonidine protective effects. Second, acute blockade of serotonergic systems also potentiates the clonidine protective effects on naloxoneinduced conditioned place aversion.

The 5,7-DHT-lesioned morphine-dependent rats develop a classic naloxone-induced conditioned place aversion. Moreover, at the higher doses of naloxone, lesioned rats display the same strategy of avoidance as do the shamoperated rats, spending more time in the saline-paired side (the 'safe' compartment). Thus, the 5-HT lesion does not alter the capacity for classical conditioning in morphinedependent rats or their ability to integrate environmental cues to refine their behavior (Bienkowski et al, 1997).

However, the results indicate that the 5-HT lesioned rats are more sensitive to clonidine since conditioned place aversion is inhibited by $25 \mu \mathrm{g} / \mathrm{kg}$ of clonidine, whereas a much higher dose $(200 \mu \mathrm{g} / \mathrm{kg})$ is required in the shamoperated rats (Caille et al, 1999b). These striking findings provide new evidence for the possible involvement of a 5-HT/NA interaction in the opiate-withdrawal-induced aversive response. Interestingly, we observed that the 5,7DHT lesion enhances the protective effect of clonidine on naloxone-induced conditioned place aversion, but not the concomitant somatic symptoms (Caille et al, 1999a). Although the somatic and motivational aspects of the opiate withdrawal syndrome cannot be completely disso- 
ciated, our results support previous work indicating that they are mediated by different neurobiological processes and can be elicited independently of each other (Delfs et al, 2000; Maldonado et al, 1992; Stinus et al, 1990).

Acute inhibition of 5-HT release is induced by low doses of a 5-HT1A receptor agonist (8-OH-DPAT) in order to activate a negative feedback via the specific stimulation of 5-HT1A autoreceptors (Goodwin et al, 1987). 8-OH-DPAT did not induce either a place preference or a place aversion in morphine-dependent rats. Our results show that 8-OHDPAT, on its own, tended to reduce naloxone-induced conditioned place aversion but was unable to block it completely. The fact that 8-OH-DPAT may have intrinsic protective properties that would influence the interaction with clonidine cannot be discarded. 8-OH-DPAT coadministered with a low dose of clonidine $(50 \mu \mathrm{g} / \mathrm{kg})$, which was unable to block naloxone-induced place aversion on its own (Caille et al, 1999b), blocked naloxone-induced place aversion. Doses of 8-OH-DPAT $(10-100 \mu \mathrm{g} / \mathrm{kg})$ totally blocked naloxone-induced conditioned place aversion. Thus, the potentiation of clonidine effects appears to derive from an inhibition of 5-HT activity. The experiments with 8-OH-DPAT rule out the possibility of postlesion adaptive mechanisms in the potentiation of the clonidine effects following DR and MR 5-HT neuron lesion.

In an earlier study by Schulteis et al (1998), it was observed that a subcutaneous injection of clonidine $20 \mathrm{~min}$ before naloxone, instead of an intraperitoneal injection $60 \mathrm{~min}$ before, increased clonidine potency. Thus, the serotonergic manipulation allows us to reproduce the augmentation of clonidine protection on naloxone-induced place aversion.

An important issue in the present study was to consider that inhibition of 5-HT transmission may potentiate the ability of clonidine to produce a conditioned place preference, a competing response to the conditioned place aversion produced by naloxone-induced withdrawal in morphine-dependent rats. Indeed, it has been shown that clonidine induced conditioned place preference when administered at high doses (at least $200 \mu \mathrm{g} / \mathrm{kg}$ ) (Asin and Wirtshafter, 1985; Tierney et al, 1988). To address this question, rats were tested with a subthreshold dose of clonidine $(50 \mu \mathrm{g} / \mathrm{kg})$ and 8-OH-DPAT, without naloxone. Results indicate clearly that the interaction does not enhance clonidine appetitive properties since rats do not develop a conditioned place preference. Thus, these results strengthen the specificity of the observed effects on clonidine protection.

When used in opiate detoxification therapy, clonidine has notable side effects because of its high dosage, which may contraindicate its use in the treatment of acute opiate withdrawal (Gerra et al, 2001). Therefore, we have determined the threshold dose of clonidine that inhibits naloxone-induced place aversion when coadministered with 8-OH-DPAT. Clonidine is effective at a dose of $25 \mu \mathrm{g} / \mathrm{kg}$, while $200 \mu \mathrm{g} / \mathrm{kg}$ is required to attenuate opiate withdrawal in control rats (Caille et al, 1999b; Esposito et al, 1987; Kimes et al, 1990). Thus, acute inhibition of 5-HT systems leads to a reduction of clonidine dose, giving equivalent protection of the naloxone-induced aversive response in morphine-dependent rats.
One hypothesis to explain the serotonin-NA interaction would be an impairment of the rat's learning capacities during the conditioning phase. However, studies have shown that clonidine given alone to nondependent rats induces conditioned place preference (Cervo et al, 1993; Tierney et al, 1988). Moreover, in our study, when morphine-dependent rats received either 8-OH-DPAT or low doses of clonidine, they still developed a naloxoneinduced conditioned place aversion. Although these data suggest that clonidine and 8-OH-DPAT do not impair place aversion conditioning, the possibility of a learning deficit induced by the drug combination cannot be eliminated.

Opiate-withdrawal-precipitated conditioned avoidance is in part dependent on the activation of corticotropinreleasing-factor (CRF) systems in the amygdala. Injection of a CRF antagonist into the central nucleus of the amygdala reduces the aversive behavioral consequences of conditioned morphine withdrawal (Heinrichs et al, 1995). Furthermore, amygdala 5-HT innervation is required for stress-induced activation of the hypothalamo-pituitaryadrenocortical (HPA) axis (Feldman et al, 1998). Interestingly, low doses of clonidine $(10-40 \mu \mathrm{g} / \mathrm{kg}$ ) have been found to block the stress-induced resumption of heroin seeking in rats (Shaham et al, 2000). Low doses of clonidine inhibit NA release via stimulation of alpha-2 adrenergic autoreceptors (Cooper et al, 1986). Taken together, these results suggest that chronic opiate administration may induce an opponent process involving activation of the brain CRF and HPA axis, which is unmasked during opiate withdrawal (Heinrichs et $a l$, 1995). Then, inhibiting 5-HT and NA transmissions would continue to block CRF/ HPA activity. Consistent with this hypothesis, we have found that the withdrawal-induced aversive response is totally blocked by a combination of acute inhibition of 5-HT transmission and low dose of clonidine $(25 \mu \mathrm{g} / \mathrm{kg})$.

In conclusion, chronic as well as acute inhibition of serotonin transmission potentiated clonidine effects on naloxone-induced conditioned place aversion in morphinedependent rats. These results suggest that a combined use of serotonergic and noradrenergic compounds might be a new pharmacological means for treating the acute opiate withdrawal syndrome.

\section{ACKNOWLEDGEMENTS}

This study was supported by grants from the University of Bordeaux 2, the Centre National de la Recherche Scientifique (CNRS), the Conseil Régional d'Aquitaine, the MILDT $\left(\mathrm{N}^{\circ}\right.$ 96C02), the Spanish-French Integrated Action (HF-97220 and 97-160) and National Institutes of Health (USA) grant DA04043 from the National Institute on Drug Abuse. This is publication number 12922-NP from The Scripps Research Institute. The authors would like to thank Mike Arends for his editorial assistance.

\section{REFERENCES}

Acquas E, Carboni E, Garau L, Di Chiara G (1990). Blockade of acquisition of drug-conditioned place aversion by 5HT3 antagonists. Psychopharmacology 100: 459-463.

Asin KE, Wirtshafter D (1985). Clonidine produces a conditioned place preference in rats. Psychopharmacology 85: 383-385. 
Azmitia EC, Segal M (1978). An autoradiographic analysis of the differential ascending projections of the dorsal and median raphe nuclei in the rat. J Comp Neurol 179: 641-667.

Beique JC, Lavoie N, de Montigny C, Debonnel G (1998). Affinities of venlafaxine and various reuptake inhibitors for the serotonin and norepinephrine transporters. Eur J Pharmacol 349: 129-132.

Bienkowski P, Iwinska K, Piasecki J, Kostowski W (1997). 5,7dihydroxytryptamine lesion does not affect ethanol-induced conditioned taste and place aversion in rats. Alcohol 14: 439-443.

Bjorklund A, Hokfelt T, Kuhar MJ (1984). Classical Transmitters and Transmitter Receptors in the CNS, Part II. (series title: Handbook of Chemical Neuroanatomy. Vol. 3). Elsevier: Amsterdam.

Blasig J, Papeschi R, Gramsch C, Herz A (1976). Central serotonergic mechanisms and development of morphine dependence. Drug Alcohol Depend 1: 221-239.

Caille S, Espejo EF, Cador M, Stinus L (1999a). Involvement of serotonin neurotransmission in opiate dependence. Behav Pharmacol 10: S14.

Caille S, Espejo EF, Reneric JP, Cador M, Koob GF, Stinus L (1999b). Total neurochemical lesion of noradrenergic neurons of the locus coeruleus does not alter either naloxone-precipitated or spontaneous opiate withdrawal nor does it influence ability of clonidine to reverse opiate withdrawal. J Pharmacol Exp Ther 290: 881-892.

Cervo L, Rochat C, Romandini S, Samanin R (1981). Evidence of a preferential role of brain serotonin in the mechanisms leading to naloxone-precipitated compulsive jumping in morphine-dependent rats. Psychopharmacology 74: 271-274.

Cervo L, Romandini S, Samanin R (1983). Evidence that 5hydroxytryptamine in the forebrain is involved in naloxoneprecipitated jumping in morphine-dependent rats. Br J Pharmacol 79: 993-996.

Cervo L, Rossi C, Samanin R (1993). Clonidine-induced place preference is mediated by alpha 2 -adrenoceptors outside the locus coeruleus. Eur J Pharmacol 238: 201-207.

Charney DS, Sternberg DE, Kleber HD, Heninger GR, Redmond Jr DE (1981). The clinical use of clonidine in abrupt withdrawal from methadone: Effects on blood pressure and specific signs and symptoms. Arch Gen Psychiatry 38: 1273-1277.

Christie MJ, Williams JT, Osborne PB, Bellchambers CE (1997). Where is the locus in opioid withdrawal? Trends Pharmacol Sci 18: $134-140$.

Cooper JR, Bloom FE, Roth RH (1986). The Biochemical Basis of Neuropharmacology. Oxford University Press: New York.

Delfs JM, Zhu Y, Druhan JP, Aston-Jones G (2000). Noradrenaline in the ventral forebrain is critical for opiate withdrawal-induced aversion. Nature 403: 430-434.

Dugast C, Suaud-Chagny MF, Gonon F (1994). Continuous in vivo monitoring of evoked dopamine release in the rat nucleus accumbens by amperometry. Neuroscience 62: 647-654.

Esposito E, Kruszewska A, Ossowska G, Samanin R (1987). Noradrenergic and behavioral effects of naloxone injected in the locus coeruleus of morphine-dependent rats and their control by clonidine. Psychopharmacology 93: 393-396.

Feldman S, Newman ME, Gur E, Weidenfeld J (1998). Role of serotonin in the amygdala in the hypothalamo-pituitaryadrenocortical responses. Neuroreport 9: 2007-2009.

Gellert VF, Holtzman SG (1978). Development and maintenance of morphine tolerance and dependence in the rat by scheduled access to morphine drinking solutions. J Pharmacol Exp Ther 205: 536-546.

Gerra G, Zaimovic A, Giusti F, Di Gennaro C, Zambelli U, Gardini $S$ (2001). Lofexidine versus clonidine in rapid opiate detoxification. J Subst Abuse Treat 21: 11-17.

Gold LH, Stinus L, Inturrisi CE, Koob GF (1994). Prolonged tolerance, dependence and abstinence following subcutaneous morphine pellet implantation in the rat. Eur J Pharmacol 253: 45-51.
Gold MS, Redmond DE, Kleber Jr HD (1978). Clonidine in opiate withdrawal. Lancet 1: 929-930.

Goodwin GM, De Souza RJ, Green AR, Heal DJ (1987). The pharmacology of the behavioural and hypothermic responses of rats to 8-hydroxy-2-(di- $n$-propylamino)tetralin (8-OH-DPAT). Psychopharmacology 91: 506-511.

Heinrichs SC, Menzaghi F, Schulteis G, Koob GF, Stinus L (1995). Suppression of corticotropin-releasing factor in the amygdala attenuates aversive consequences of morphine withdrawal. Behav Pharmacol 6: 74-80.

Higgins G, Nguyen P, Joharchi N, Sellers EM (1991). Effects of 5 HT3 receptor antagonists on behavioural measures of naloxoneprecipitated opioid withdrawal. Psychopharmacology 105: 322-328.

Ho IK, Loh HH, Way EL (1972). Influence of 5,6-dihydroxytryptamine on morphine tolerance and physical dependence. Eur $J$ Pharmacol 21: 331-336.

Kimes AS, Bell JA, London ED (1990). Clonidine attenuates increased brain glucose metabolism during naloxone-precipitated morphine withdrawal. Neuroscience 34: 633-644.

Macedo TR, Relvas J, Fontes Ribeiro CA, Pacheco F, Morgadinho MT, Pinto CM (2000). Plasma catecholamines during an ultrarapid heroin detoxification. Ann N Y Acad Sci 914: 303-310.

Maldonado R, Stinus L, Gold LH, Koob GF (1992). Role of different brain structures in the expression of the physical morphine withdrawal syndrome. J Pharmacol Exp Ther 261: 669-677.

Rafieian-Kopaei M, Gray AM, Spencer PS, Sewell RD (1995). Contrasting actions of acute or chronic paroxetine and fluvoxamine on morphine withdrawal-induced place conditioning. Eur J Pharmacol 275: 185-189.

Samanin R, Cervo L, Rochat C (1980). Changes of physical morphine dependence in rats chronically treated with drugs acting on brain 5-hydroxytryptamine. J Pharm Pharmacol 32: 150.

Schulleis G, Stinus L, Risbrough V, Kods GF (1990). Clonidine blocks acquisition but not expression of conditioned optate withdrawal in rats. Neuropsychopharmacology 19: 406-416.

Schulteis G, Markou A, Gold LH, Stinus L, Koob GF (1994). Relative sensitivity to naloxone of multiple indices of opiate withdrawal: a quantitative dose-response analysis. J Pharmacol Exp Ther 271: 1391-1398.

Shaham Y, Highfield D, Delfs J, Leung S, Stewart J (2000). Clonidine blocks stress-induced reinstatement of heroin seeking in rats: an effect independent of locus coeruleus noradrenergic neurons. Eur J Neurosci 12: 292-302.

Silverstone PH, Done C, Sharp $\mathrm{T}$ (1993). In vivo monoamine release during naloxone-precipitated naloxone withdrawal. Neuroreport 4: 1043-1045.

Spampinato U, Invernizzi R, Samanin R (1984). Evidence of serotonin involvement in the effect of morphine on dopamine metabolism in the rat nucleus accumbens but not in the striatum. Pharmacol Res Commun 16: 519-523.

Stinus L, Caille S, Koob GF (2000). Opiate withdrawal induced place aversion lasts for up to 16 weeks. Psychopharmacology 149: 115-120.

Stinus L, Le Moal M, Koob GF (1990). Nucleus accumbens and amygdala are possible substrates for the aversive stimulus effects of opiate withdrawal. Neuroscience 37: 767-773.

Tao R, Auerbach SB (1995). Involvement of the dorsal raphe but not median raphe nucleus in morphine-induced increases in serotonin release in the rat forebrain. Neuroscience 68: 553-561.

Tierney C, Nadaud D, Koenig-Berard E, Stinus L (1988). Effects of two alpha2-agonists, rilmenidine and clonidine, on the morphine withdrawal syndrome and their potential addictive properties in rats. Am J Cardiol 61: 35D-38D.

Vertes R (1991). A PHA-L analysis of ascending projections of the dorsal raphe nucleus in the rat. J Comp Neurol 313: 643-668.

Way EL, Loh HH, Shen F (1968). Morphine tolerance, physical dependence and synthesis of brain 5-hydroxytryptamine. Science 162: 1290-1292. 